\title{
Determination of Acrylamide in Chinese Foods by GC-Ion Trap MS Using 2-Bromopropenamide and 2-Bromopropenamide- ${ }^{13} \mathrm{C}_{3}$
}

\author{
WEI-CHIH CHENG ${ }^{1,2}$, SHUN-WEN HSIAO ${ }^{1,2}$, SHIN-SHOU CHOU ${ }^{2}$, LUCY SUN-HWANG ${ }^{1}$, \\ T. J. LU ${ }^{1}$ AND AN-I YEH ${ }^{1 *}$ \\ 1. Institute of Food Science and Technology, National Taiwan University, 1, Sec. 4, Roosevelt Rd., Taipei 106, Taiwan, R.O.C. \\ 2. Bureau of Food and Drug Analysis, Department of Health, Executive Yuan, 161-2, Kunyang St., Taipei 115, Taiwan, R.O.C.
}

(Received: October 27, 2005; Accepted: March 23, 2006)

\begin{abstract}
GC/Ion-Trap MS has been employed to determine the acrylamide content in some Chinese foods. The brominated derivative, 2,3-dibromopropionamide (2,3-DBPA), was found unstable and was converted to 2-bromopropenamide (2-BPA) during the GC/MS analysis. Lowering the injector temperature reduced the formation of 2-BPA. Triethylamine was used to convert 2,3-DBPA to 2$\mathrm{BPA}$, which was stable during the analysis. The ${ }^{13} \mathrm{C}_{3}$-labeled acrylamide was used as the internal standard. The ratio of peak area of 2-bromopropenamide $(\mathrm{m} / \mathrm{z} 151)$ to 2-bromopropenamide- ${ }^{13} \mathrm{C}_{3}(\mathrm{~m} / \mathrm{z} 154)$ was used for quantification. The recoveries were between $102 \%$ and $110 \%$ when wheat flour dough was spiked with acrylamide at 10 to $50 \mu \mathrm{g} / \mathrm{kg}$, with the detection limit of $5 \mu \mathrm{g} / \mathrm{kg}$. Among the Chinese foods tested (fried gluten, instant noodles, and twisted cruller), old twisted cruller consisted the most acrylamide (890-900 $\mu \mathrm{g} / \mathrm{kg}$ ), whereas fried gluten yielded the least acrylamide (less than $20 \mu \mathrm{g} / \mathrm{kg}$ ), probably due to the absence of starch.
\end{abstract}

Key words: acrylamide, GC/Ion-Trap MS, 2-bromopropenamide, Chinese foods

\section{INTRODUCTION}

Acrylamide is a synthetic monomer that is used as a precursor in the production of polyacrylamide, which has been used in water or wastewater treatment, paper processing and electrophoretic separations. In April 2002, the Swedish National Food Administration revealed the high content of acrylamide in various foods, particularly fried and baked starchy foods ${ }^{(1)}$. The presence of acrylamide in foods has arisen the caution of food scientists worldwide and has been confirmed by the health agencies of different countries including United States, United Kingdom, Norway, Switzerland, Germany, Japan, Hong Kong, and Austria ${ }^{(2,3,4,5)}$. An understanding of the distribution of acrylamide in foods is essential to conduct risk assessment. Nevertheless, since most of the available data are on western foods, the presence of acrylamide in oriental foods needs to be investigated.

Barber et al. ${ }^{(6)}$ have shown that acrylamide is metabolized to glycidamide, a neurotxic epoxide. Acrylamide is also recognized as a potential mutagen and reproductive toxicant. The International Agency for Research on Cancer (IARC, 1994) ${ }^{(7)}$ has labeled acrylamide Group 2A, a probable human carcinogen. The total average dietary intake of acrylamide in Sweden was estimated to be $0.5 \mu \mathrm{g} / \mathrm{kg}$ body weight/day. Based on this finding, the risk assessments by US EPA and WHO imply that dietary intake of acrylamide could be associated

\footnotetext{
* Author for correspondence. Tel: +886-2-33664121;

Fax: +886-2-23620849; E-mail: yehs@ntu.edu.tw
}

with potential health risks ${ }^{(2)}$. To evaluate the risk of acrylamide on human health, research on acrylamide is need to achieve a better understanding of human exposure and possible health effects.

Numerous methods have been used to analyze acrylamide in water ${ }^{(8)}$. Among the methods, gas chromatography (GC) using the 2,3-dibromopropionamide $\left(2,3\right.$-BPA) derivatives ${ }^{(9,10)}$ and the selective and sensitive ECD are most suitable for trace level determination of acrylamide in environmental and biological samples. GC/MS and LC/MS/MS are two major detection methods for foods at detection level of 5 and $10 \mu \mathrm{g} / \mathrm{kg}$, respectively ${ }^{(1,11)}$. The LC/MS/MS is simpler and preferable due to the elimination of bromination ${ }^{(12,13)}$. GC/MS has cheaper operation cost (US\$ 150-200 per assay) than LC/MS/MS

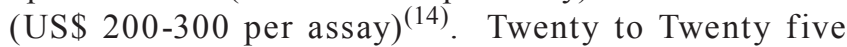
assays/day/person can be done by LC/MS/MS while only 5-15 assays/day/person by GC/MS. Analysis using GC/MS, although not as simple and fast as that using $\mathrm{LC} / \mathrm{MS} / \mathrm{MS}$, enables the analysis of difficult matrices, such as cocoa, soluble coffee, molasses or malt (Hoeicke et al., 2004) ${ }^{(15)}$.

The availability of LC/MS/MS is limited in the food industry of Taiwan. The decomposition of 2,3-DBPA to 2-bromopropenamide (2-BPA) might result in deviation by GC/MS method. This paper has attempted to evaluate the role of bromination on determining acrylamide content by GC/Ion-Trap MS using ${ }^{13} \mathrm{C}_{3}$-labeled acrylamide as internal standard and 
to understand the distribution of acrylamide in some traditional Chinese foods, including fried gluten, instant noodles, and twister cruller.

\section{MATERIALS AND METHODS}

\section{Materials}

Several product categories including fried gluten, instant noodles, cup noodles, twisted cruller, old twisted cruller, and potato chips were purchased from retail stores, supermarkets, and restaurants in Taipei. To study the effect of frying temperature on the acrylamide content, twisted crullers were collected after being fried at 182 or $209^{\circ} \mathrm{C}$ for 1,3 , and $5 \mathrm{~min}$ at a breakfast restaurant in Taipei. The temperature of the frying oil was measured using a thermocouple. The $\mathrm{pH}$ of the twisted cruller dough before frying was measured as $8.61 \pm 0.01$. After frying at $209^{\circ} \mathrm{C}$ for $5 \mathrm{~min}$, some products were left in the frying oil overnight without continuous heating and were referred to old twisted cruller. The acrylamide content in commercial potato chips was also determined for comparison with previously reported data. Wheat flour dough was used to determine the recovery and the detection limit.

\section{Internal Standard Solutions}

The internal standard solution of $1 \mu \mathrm{g} / \mathrm{mL}$ was prepared as follows. One mililiter of $1,2,3-{ }^{13} \mathrm{C}_{3}$-acrylamide obtained from Cambridge Isotope Laboratory (Andover, MA, USA) (1 mg/mL) was made up to 100 $\mathrm{mL}$ with methanol supplied by Sigma Co. (St. Louis, MO, USA). One mililiter of the solution consisting of $10 \mu \mathrm{g} / \mathrm{mL}$ internal standard was made up to $10 \mathrm{~mL}$ with deionized water. The final solution consisted of $1 \mu \mathrm{g} / \mathrm{mL}$ internal standard and was designated as the stock ISTD.

\section{Acrylamide Solutions}

Acrylamide $(99.9 \%$ purity, purchased from J. T. Baker (Phillipsburg, NJ, USA)) was weighed $(0.1 \mathrm{mg})$ and transferred to a $100 \mathrm{~mL}$ volumetric flask, and then the deionized water was added to make the volume to 100 $\mathrm{mL}$. The acrylamide solution was further diluted with deionized water to $5,10,20,40,60$, and $80 \mu \mathrm{g} / \mathrm{kg}$ for calibration.

\section{Sample Preparation}

Samples (commercial products or wheat flour dough) were pulverized by a food processor and weighed $(5 \mathrm{~g})$ into a beaker. After addition of $30 \mathrm{~mL}$ of deionized water, the mixture was homogenized for $3 \mathrm{~min}$ and shaken at high speed on a horizontal shaker for $1 \mathrm{hr}$. The homogenate was poured into a centrifuge tube and centrifuged (Labofuge 400, Heraeus Instrument Inc., Hanau, German) at 3,500 rpm for $15 \mathrm{~min}$ at $30^{\circ} \mathrm{C}$. The supernatant was transferred to a $10 \mathrm{~mL}$ brown test tube for further purification. For the recovery test, $5 \mathrm{~g}$ of wheat flour dough was spiked with acrylamide solution at a concentration of 10,20 , and $50 \mu \mathrm{g} /$ $\mathrm{kg}$. Three replicates were conducted for the determination of the recovery. The detection and quantitation limit was determined using wheat flour dough, which was spiked with various concentration of acrylamide. The limit of detection and quantitation limit was estimated as the peak area ratio of signal to noise ( $\mathrm{S} / \mathrm{N}$ ratio) no less than five and ten respectively.

Acrylamide is water-soluble and can be extracted using deionized water. The ratio of sample to water and the extraction time is critical for sample preparation. Various ratios of sample to water have been used in literatures, such as $1: 20^{(3)}, 1: 10^{(1,16)}, 1: 6$ to $1: 8^{(17)}$ and $1: 4^{(9,18)}$. From the preliminary test, a ratio of $1: 6$ with an extraction time of one hour was selected. Since shaking was helpful for extracting acrylamide from samples, the concentration of acrylamide in the sample was appropriate for $\mathrm{GC} / \mathrm{MS}$ analysis.

\section{Purification}

By following the method of FDA (2002) ${ }^{(16)}$ and Becalski et al. $(2003)^{(18)}$ for LC/MS/MS, the $3 \mathrm{~mL}$ of supernatant was added to a solid-phase extraction (SPE) using an Oasis HLB cartridge (Waters, Milford, MA, USA) connected in tandem to an Oasis MCX cartridge (Waters). After discarding the first $\mathrm{mL}$ of the eluate, the remaining eluate was collected in a $10 \mathrm{~mL}$ brown test tube. The cartridges were further eluted with $4 \mathrm{~mL}$ of water into the same tube and the total elute was $6 \mathrm{~mL}$. Both Oasis HLB and MCX cartridges were conditioned with methanol ( $5 \mathrm{~mL}$ and $3 \mathrm{~mL}$, respectively) and water (5 $\mathrm{mL}$ and $3 \mathrm{~mL}$, respectively) before the above procedures.

\section{Bromination}

The SPE eluate was transferred to a capped test tube covered with aluminum foil. Afterwards, the bromination reagent $(6 \mathrm{~mL})$ was added and stored at $4^{\circ} \mathrm{C}$ for $15 \mathrm{hr}$ for the bromination. When the acrylamide solution was used for calibration, a mixture of $2 \mathrm{~mL}$ of acrylamide solution and $4 \mathrm{~mL}$ of deionized water was used instead of the SPE eluate. The bromination was terminated by adding $60 \mu \mathrm{L}$ of sodium thiosulfate $(1 \mathrm{M})$ and the excess bromine was reduced to colourless. The method of Castle $(1993)^{(9)}$ was used to prepare the bromination reagent by dissolving $20 \mathrm{~g}$ of potassium bromide (Sigma Co., St. Louis, MO, USA) in $16 \mathrm{~mL}$ of saturated bromine solution, and adding $1 \mathrm{~mL}$ of hydrobromic acid (Sigma Co.). A total volume of $100 \mathrm{~mL}$ was obtained by adding deionized water. The reagent was stored at $4^{\circ} \mathrm{C}$ before use. The saturated bromine solution was prepared by adding bromine $(3 \mathrm{~mL})$ with deionized water $(80 \mathrm{~mL})$ and shaking to be a clear solution in an icewater bath for $1 \mathrm{hr}$. 
After the bromination, the solution was transferred into a $100-\mathrm{mL}$ separatory funnel. Ethyl acetate $(20 \mathrm{~mL})$ (Riedel-deHaen, Seelze, Germany) was employed to extract the brominated compound by using a vertical shaker at high speed for $20 \mathrm{~min}$. The extraction procedures were repeated twice. The extract was transferred into another separatory funnel with the addition of $4 \mathrm{~g}$ of anhydrous sodium sulfate (FSA Laboratory Supplies Co., Loughborough, UK), followed by $20 \mathrm{~min}$ of shaking. The dehydrated solution was transferred to a condensation vessel. The possible residue in the funnel was washed twice with ethyl acetate (10 $\mathrm{mL}$ ) and also transferred to the condensation vessel. The solvent (ethyl acetate) was evaporated at $40^{\circ} \mathrm{C}$ with using a rotary evaporator (BÜCHI RE 11 Rotavapor, BÜCHI AG, Switzerland) at reduced pressure (220 Pa). The residue was transferred into a micro-grass tube and blown gently with nitrogen to dryness. The tube was kept at $4{ }^{\circ} \mathrm{C}$ and ethyl acetate was added again to make up a total volume of $40 \mu \mathrm{L}$. The brominated compound (2,3-DBPA) was further converted to 2-BPA by adding $10 \mu \mathrm{L}$ of triethylamine (Sigma Co.). When the dibrominated compound was used for the GC/MS analysis, no triethylamine was added.

\section{GC/Ion-trap MS Analysis}

GC (CP-3800, Varian, Walnut Creek, CA, USA)/ Ion-Trap MS (Saturan 2200, Varian) equipped with MS/ MS, 3400CX GC, 1078 or 1077 injector and 8200 autosampler was employed to conduct the analysis. The injector temperature was $200^{\circ} \mathrm{C}$, and the temperature programme used was as follows: isothermal for $1 \mathrm{~min}$ at $50^{\circ} \mathrm{C}$, increased to $240^{\circ} \mathrm{C}$ at a rate of $5^{\circ} \mathrm{C} / \mathrm{min}$, and isothermal for $5 \mathrm{~min}$. Helium (purity 99.9995\%) was used as the carrier gas at a flow rate of $1.0 \mathrm{~mL} / \mathrm{min}$. A HP-5MS column (J\&W Scientific, Folsom, CA, and USA) of $30 \mathrm{~m}$ length $\times 0.25 \mathrm{~mm}$ (inside diameter) with a 0.25 $\mu \mathrm{m}$ film thickness was used for the GC. One micro liter of the sample was introduced into the GC/MS system by splitless injection method with the split vent closed for $0.75 \mathrm{~min}$. The temperature of transfer line and manifold of the MS was set at $170^{\circ} \mathrm{C}$ and $190^{\circ} \mathrm{C}$, respectively. The analysis was performed using electron inoization (70 $\mathrm{eV}$ ) and selected ion monitoring. The ions monitored for identification of the analyte, 2-BPA, were $\left[\mathrm{C}_{3} \mathrm{H}_{5}{ }^{81} \mathrm{BrNO}\right]^{+}$ $=151,\left[\mathrm{C}_{3} \mathrm{H}_{5}{ }^{79} \mathrm{BrNO}\right]^{+}=149,\left[\mathrm{C}_{2} \mathrm{H}_{3}{ }^{81} \mathrm{Br}\right]^{+}=108$, $\left[\mathrm{C}_{2} \mathrm{H}_{3}{ }^{79} \mathrm{Br}\right]^{+}=106$, and $\left[\mathrm{C}_{3} \mathrm{H}_{5} \mathrm{NO}\right]^{+}=70$ using $\mathrm{m} / \mathrm{z} 151$ for quantification. When no triethylamine was added, the ions monitored for identification of the analyte, 2,3-BPA, were $\left[\mathrm{C}_{3} \mathrm{H}_{4}{ }^{81} \mathrm{BrNO}\right]^{+}=152,\left[\mathrm{C}_{3} \mathrm{H}_{4}{ }^{79} \mathrm{BrNO}\right]^{+}=150,\left[\mathrm{C}_{2} \mathrm{H}_{3}{ }^{79} \mathrm{Br}\right]^{+}$ $=106$, and $\left[\mathrm{C}_{3} \mathrm{H}_{5} \mathrm{NO}\right]^{+}=70$. The ions monitored for identification of the internal standard, $2-\mathrm{BP}\left({ }^{13} \mathrm{C}_{3}\right) \mathrm{A}$, were $\left[{ }^{13} \mathrm{C}_{3} \mathrm{H}_{5}{ }^{81} \mathrm{BrNO}\right]^{+}=154,\left[{ }^{13} \mathrm{C}_{3} \mathrm{H}_{5}{ }^{79} \mathrm{BrNO}^{+}=152\right.$, $\left.\left[{ }^{13} \mathrm{C}_{2} \mathrm{H}_{3}{ }^{81} \mathrm{Br}\right]\right]^{+}=110,\left[{ }^{13} \mathrm{C}_{2} \mathrm{H}_{3}{ }^{79} \mathrm{Br}\right]^{+}=108$, and $\left.\left[{ }^{13} \mathrm{C}_{3} \mathrm{H}_{5} \mathrm{NO}\right]\right]^{+}$ $=73$ using $\mathrm{m} / \mathrm{z} 154$ for quantificlation. The spectrum of analyte should match that of the standard. Quantification was performed by comparison with a calibration curve $(5-80 \mu \mathrm{g} / \mathrm{kg})$ for the area ratio of the fragment ion peak of 2-BPA $(\mathrm{m} / z \mathrm{151})$ to that of the internal standard $(\mathrm{m} / z \mathrm{154})$. The sample with concentration greater than the calibration range was diluted before GC/MS analysis.

\section{RESULTS AND DISCUSSION}

\section{Bromination and Detection}

The molecule of acrylamide is so small that it cannot be easily detected by EI mode in GC/MS system. Bromination is used to enlarge the molecular weight for the necessary analysis ${ }^{(1,12,19)}$. The brominated compound 2,3-DBPA has been used for quantitative determination by $\mathrm{GC} / \mathrm{MS}^{(1,17)}$ and was found to decompose to 2-BPA at the injector or the active sites at the front end of the column $^{(20,21,22)}$. Figure 1 illustrates that the injector temperature affected the formation of 2-BPA when 2,3-DBPA was introduced into the GC/MS. As the injector temperature increased from $120^{\circ} \mathrm{C}$ to $220^{\circ} \mathrm{C}$, the formation of 2-BPA was increased as indicated by the increase in the intensity of the extracted ion. Although the content of 2-BPA was slightly decreased at $250^{\circ} \mathrm{C}$, the intensity of 2,3-DBPA kept decreasing, indicating the detection of 2,3-DBPA might be reduced at very high temperature. At $120^{\circ} \mathrm{C}$, the decomposition of 2,3-DBPA was reduced, but still existed. Although Chen et al. (2002) ${ }^{(23)}$ reported that

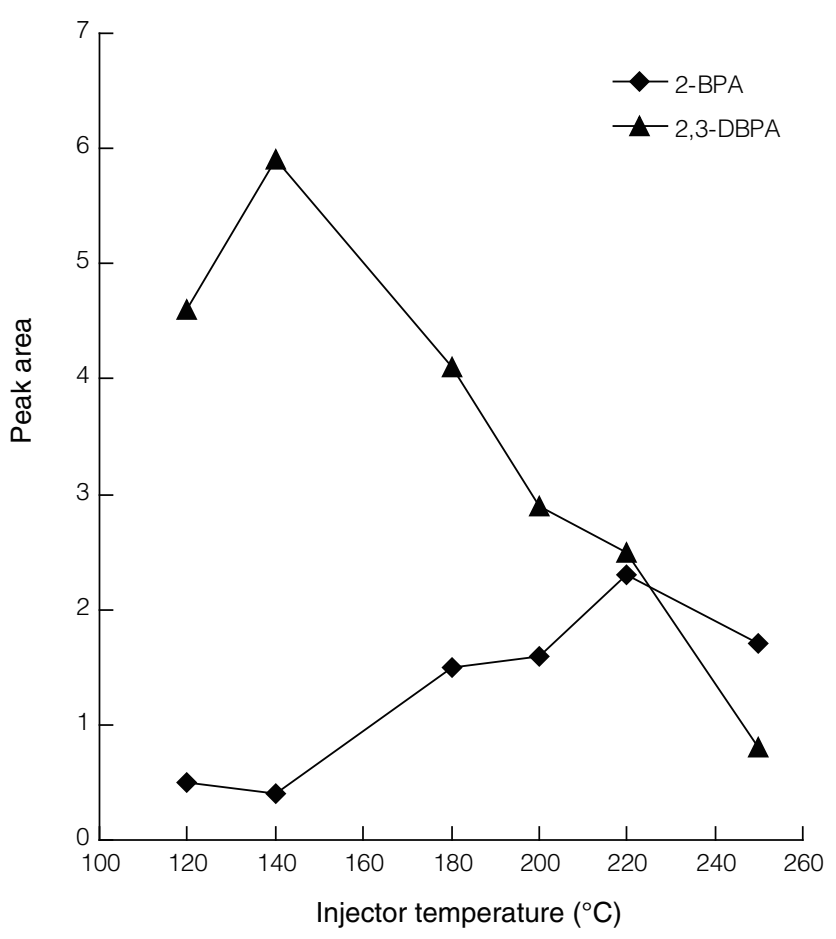

Figure 1. Injector temperature affected the decomposition of 2,3-dibromopropionamide (2,3-BPA) to 2-bromopropenamide (2-BPA). Peak area was measured by the intensity of extracted ion $(\mathrm{m} / z 151$ for 2-BPA, $\mathrm{m} / z 152$ for 2,3-DBPA) in GC-MS. 
lowering the injector temperature to $140^{\circ} \mathrm{C}$ would prevent the decomposition of 2,3-DBPA, the results shown in Figure 1 demonstrated that decrease in the injector temperature from 220 to $140^{\circ} \mathrm{C}$ reduced the formation of 2-BPA, but could not prevent the decomposition of 2,3-DBPA. The sensitivity of the instrument was reduced at lower temperature and limited the application for reproducible analysis. The decomposition of 2,3-DBPA could result in discrepancy of data.

As reported in the literature ${ }^{(18,21)}$ that the inert material in the column for GC could prevent the decomposition of 2,3-DBPA, three non-polar columns (BPX-10, DB-5, and HP-5MS) were tested in this study. The formation of 2-BPA was still detected (data not shown). To obtain reproducible results, triethylamine was employed to convert 2,3-DBPA to 2-BPA before GC/ MS analysis in a complete and reproducible manner ${ }^{(22)}$. Figure 2 shows that only 2-BPA was detected after the sample was treated with triethylamine. In addition, the choice of internal standard also affected the precision of quantitative determination. Several compounds, including $1-{ }^{13} \mathrm{C}$-acrylamide, $1,2,3-{ }^{13} \mathrm{C}_{3}$-arylamide, ${ }^{3} \mathrm{H}$-acrylamide, $N, N$-dimethylacrylamide, and 2,3-dibromo- $N, N$ dimethylpropionamide, have been used as the internal standard ${ }^{(1,3,9,17)}$. The suitability of $N, N$-dimethylacrylamide and $1,2,3-{ }^{13} \mathrm{C}_{3}$-arylamide was compared in the preliminary study. Reproducibility was low when $N, N$-dimethylacrylamide was used. High precision and reproducibility (data not shown) were obtained by using $1,2,3-{ }^{13} \mathrm{C}_{3}$-acrylamide as the internal standard. The data concurred with the report by Tareke et al. (2002) ${ }^{(1)}$ using $1,2,3-{ }^{13} \mathrm{C}_{3}$-acrylamide

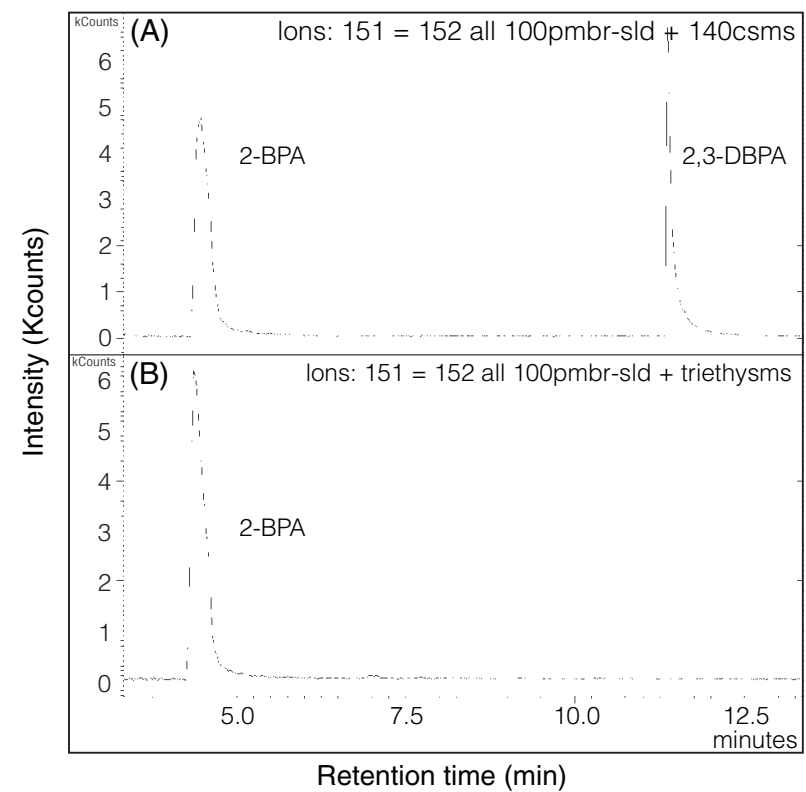

Figure 2. The GC-MS extracted ions $(\mathrm{m} / \mathrm{z} 151$ for 2 -bromopropenamide (2-BPA), $m / z 152$ for 2,3-dibromopropionamide (2,3-BPA)) chromatograms of (A) acrylamide derivative with no triethylamide treated and (B) acrylamide derivative treated with triethylamine. as the internal standard for GC/MS analysis. The full scan EI mass spectra of 2-BPA and $2-\mathrm{BP}\left({ }^{13} \mathrm{C}_{3}\right) \mathrm{A}$ are shown in Figure 3. The presence of all the characteristic ions $(\mathrm{m} / \mathrm{z}$ of $70,106,108,149$, and 151 for 2-BPA and $\mathrm{m} / \mathrm{z}$ of 73,108 , 110,152 and 154 for $\left.2-\mathrm{BP}\left({ }^{13} \mathrm{C}_{3}\right) \mathrm{A}\right)$ confirmed the analysis. The ratios of retention time for 2-BPA compared with the internal standard were found within $5 \%$ for standards, spikes, and samples ${ }^{(24)}$. The spectrum was monitored to assure reproducibility of data.

\section{Standard Curve, Recoveries and Limit of Detection}

A calibration curve (Figure 4) was established based on the area ratio of the peak area of $\mathrm{m} / z$ of 151 for 2-BPA to that of $m / z$ of 154 for 2-BP $\left({ }^{13} \mathrm{C}_{3}\right)$ determined on wheat
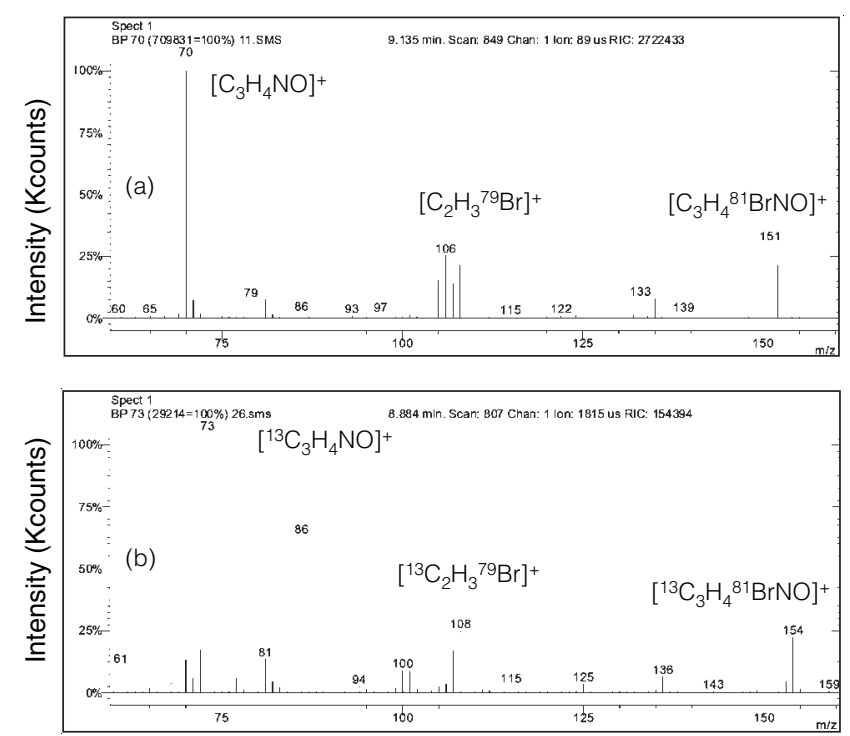

Figure 3. The GC-MS spectrum of (A) 2-bromopropenamide (2-BPA) and (B) 2-BP $\left({ }^{13} \mathrm{C}_{3}\right) \mathrm{A}$.

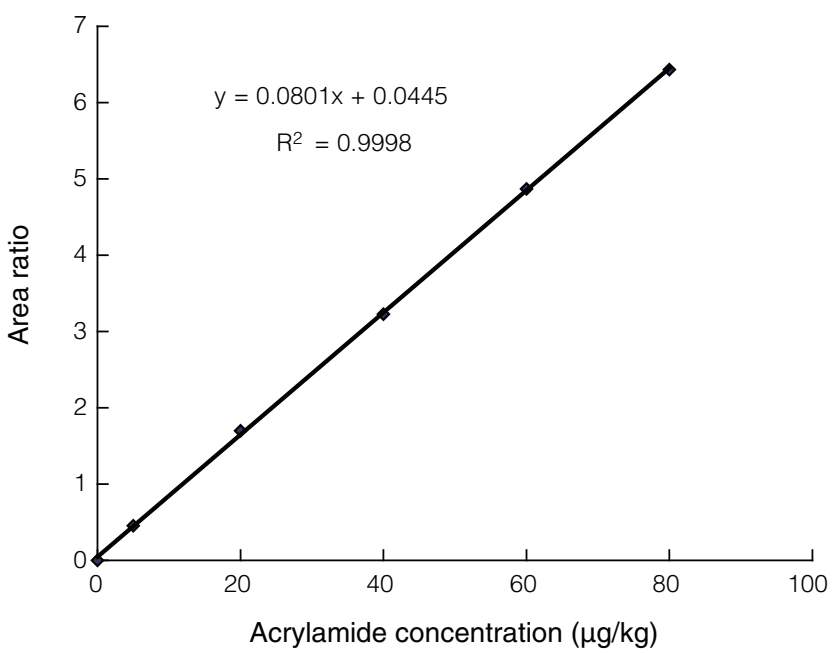

Figure 4. Standard curve of acrylamide at concentration ranged from 5 to $80 \mu \mathrm{g} / \mathrm{kg}$ using ${ }^{13} \mathrm{C}_{3}$-labeled acrylamide as an internal standard. 
flour dough spiked with acrylamide $(5-80 \mu \mathrm{g} / \mathrm{kg})$. The high coefficient of determination $\left(R^{2}=0.9998\right)$ and the average recovery between $102 \%$ and $110 \%$ indicated that the experimental procedures were reliable (Table 1). The detection limit was $5 \mu \mathrm{g} / \mathrm{kg}$ and the quantitative determination limit was $10 \mu \mathrm{g} / \mathrm{kg}$, which was similar to the literature data ${ }^{(1,11)}$.

\section{Quality Control}

Generally foods, particularly fried products, have complicated matrix for the GC/MS analysis. To assure the correct analysis, the ratio of the characteristic ion offers a way for quality control. According to the abundance percentage of mass and isotope, the ratio of $\mathrm{m} / \mathrm{z}$ of 149 to 151 should be $1.03^{(25)}$. For the acrylamide standard solution, the ratio was 0.98 (Table 2), which was very close to the theoretical value. As for the commercial products including instant noodles, twisted cruller, potato chips and fried gluten, the ratio was around 0.92 except that for fried gluten (1.02). All samples matched the spectrum of the standard solution. Thus, the method was appropriate for the determination of acrylamide in food.

\section{Survey Results}

Fried gluten and twisted cruller are generally served for breakfast. After deep-frying, the fried gluten appears like a ball that is too hard to eat (Figure 5 A). After being cooked particularly with soy sauce and peanut, the fried gluten becomes soft and elastic (Figure 5 B), and tastes delicious. Fried gluten seemed to contain the least amount of acrylamide (Table 3). In fact, three out of five brands did not show any detectable acrylamide. On the other hand, instant noodles had more acrylamide. Three out of four brands yielded acrylamide content ranged

Table 1. Recovery of acrylamde spiked into a wheat flour dough

\begin{tabular}{ccc}
\hline Spiked $(\mu \mathrm{g} / \mathrm{kg})$ & Detected $(\mu \mathrm{g} / \mathrm{kg})$ & Recovery $(\%)^{\mathrm{a}}$ \\
\hline 10 & $11,11,11$ & $110 \pm 0$ \\
20 & $19,21,21$ & $102 \pm 6$ \\
50 & $53,50,50$ & $102 \pm 3$ \\
\hline
\end{tabular}

${ }^{\mathrm{a}}$ Data are mean values of three determinations \pm standard deviation.

Table 2. The intensity and ratio of characteristic ions in commercial products

\begin{tabular}{ccc}
\hline Sample & $\begin{array}{c}\text { Intensity } \\
(\text { Kcounts, } m / z \text { 149/151) }\end{array}$ & Ratio $^{\mathrm{a}}$ \\
\hline Standard & $1987 / 2009$ & 0.98 \\
Instant noodles & $4158 / 4519$ & 0.92 \\
Fried gluten & $722 / 711$ & 1.02 \\
Twisted cruller & $835 / 897$ & 0.93 \\
Old twisted cruller & $2055 / 2228$ & 0.92 \\
Potato chips & $2969 / 3235$ & 0.92 \\
\hline
\end{tabular}

${ }^{\mathrm{a}}$ Theoretical value $=1$.
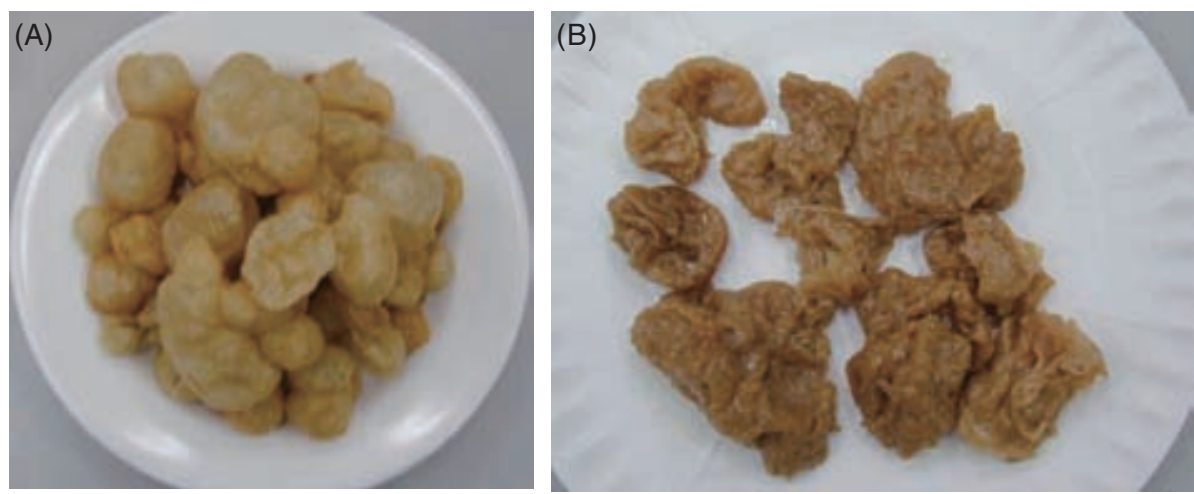

Figure 5. Appearance of fried gluten, (A) before cooking, (B) after cooking.
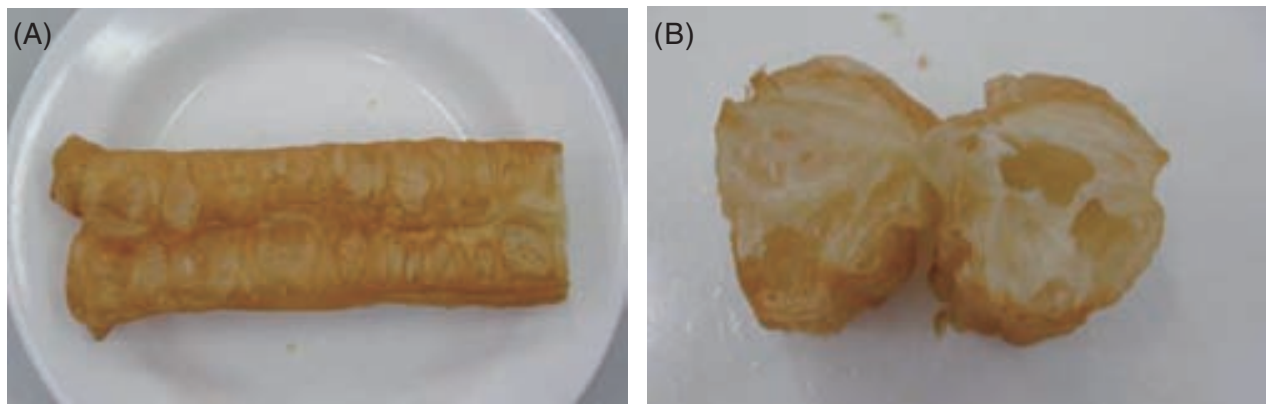

Figure 6. The appearance of (A) twisted cruller and (B) its cross section. 
Table 3. The acrylamide contents in commercial products

\begin{tabular}{|c|c|c|c|}
\hline Food item & Brand & Acrylamide $(\mu \mathrm{g} / \mathrm{kg})^{\mathrm{a}}$ & $\mathrm{n}$ \\
\hline \multirow{5}{*}{ Fried gluten } & A & $18 \pm 2.8$ & 2 \\
\hline & $\mathrm{B}$ & $15 \pm 2.9$ & 2 \\
\hline & $\mathrm{C}$ & $\mathrm{ND}^{\mathrm{b}}$ & 2 \\
\hline & $\mathrm{D}$ & ND & 2 \\
\hline & $\mathrm{E}$ & ND & 2 \\
\hline \multirow{4}{*}{ Instant noodles } & $\mathrm{F}$ & $156 \pm 1.4$ & 2 \\
\hline & G & $100 \pm 0.6$ & 2 \\
\hline & $\mathrm{H}$ & $90 \pm 1.5$ & 2 \\
\hline & I & $20 \pm 4.0$ & 2 \\
\hline \multirow{11}{*}{ Cup noodles } & $\mathrm{J}$ & 128 & 1 \\
\hline & $\mathrm{K}$ & 92 & 1 \\
\hline & $\mathrm{L}$ & $57 \pm 0.8$ & 2 \\
\hline & M & $56 \pm 3.1$ & 2 \\
\hline & $\mathrm{N}$ & $50 \pm 2.2$ & 2 \\
\hline & $\mathrm{O}$ & $40 \pm 4.8$ & 2 \\
\hline & $\mathrm{P}$ & $15 \pm 3.3$ & 2 \\
\hline & Q & $13 \pm 2.6$ & 2 \\
\hline & $\mathrm{R}$ & 25 & 1 \\
\hline & $\mathrm{S}$ & 52 & 1 \\
\hline & $\mathrm{T}$ & ND & 2 \\
\hline \multirow{2}{*}{ Potato chips } & $\mathrm{U}$ & $796 \pm 2.2$ & 2 \\
\hline & $\mathrm{V}$ & $707 \pm 9.6$ & 2 \\
\hline \multirow{2}{*}{ Twisted cruller } & W & $776 \pm 16.4$ & 2 \\
\hline & $\mathrm{X}$ & $441 \pm 7.4$ & 2 \\
\hline \multirow{2}{*}{ Old twisted cruller } & $\mathrm{Y}$ & $898 \pm 6.9$ & 2 \\
\hline & Z & $890 \pm 3.7$ & 2 \\
\hline
\end{tabular}

${ }^{\mathrm{a}}$ Data are mean values of two determination $\pm \mathrm{SD}$ except cup noodles samples $\mathrm{J}, \mathrm{K}, \mathrm{R}$ and $\mathrm{S}$.

${ }^{\mathrm{b}} \mathrm{ND}=$ Non detectable.

from 90 to $156 \mu \mathrm{g} / \mathrm{kg}$. The remaining one that showed very low acrylamide content $(20 \mu \mathrm{g} / \mathrm{kg})$. Cup noodles are similar to instant noodles, but are more expensive due to better quality of wheat flour used. Most cup noodles had acrylamide lower than $60 \mu \mathrm{g} / \mathrm{kg}$. Two of them had acrylamide content similar to instant noodles. The results were similar to those $(52,136 \mu \mathrm{g} / \mathrm{kg})$ in USA (CFSAN 2004a) $^{(26)}$, but much lower than Japanese deepfried noodles $(581 \mu \mathrm{g} / \mathrm{kg})$ reported by Ono $(2003)^{(17)}$. Two samples of potato chips (imported from USA) were found to have acrylamide content between 700 and 800 $\mu \mathrm{g} / \mathrm{kg}$. The data were in the ranges of the literatures. The acrylamide content in potato chips have been reported to be $380-800 \mu \mathrm{g} / \mathrm{kg}$ in USA (CFSAN 2004b) ${ }^{(27)}, 439-870$ $\mu \mathrm{g} / \mathrm{kg}$ in Sweden ${ }^{(1)}$, and 439-1420 $\mu \mathrm{g} / \mathrm{kg}$ in Japan ${ }^{(3)}$. Based on the data on potato chips and cup noodles, the GC/MS analysis method developed in this study was reliable.

Two twisted crullers, purchased from different retail stores, were found to have acrylamide content of 441 and

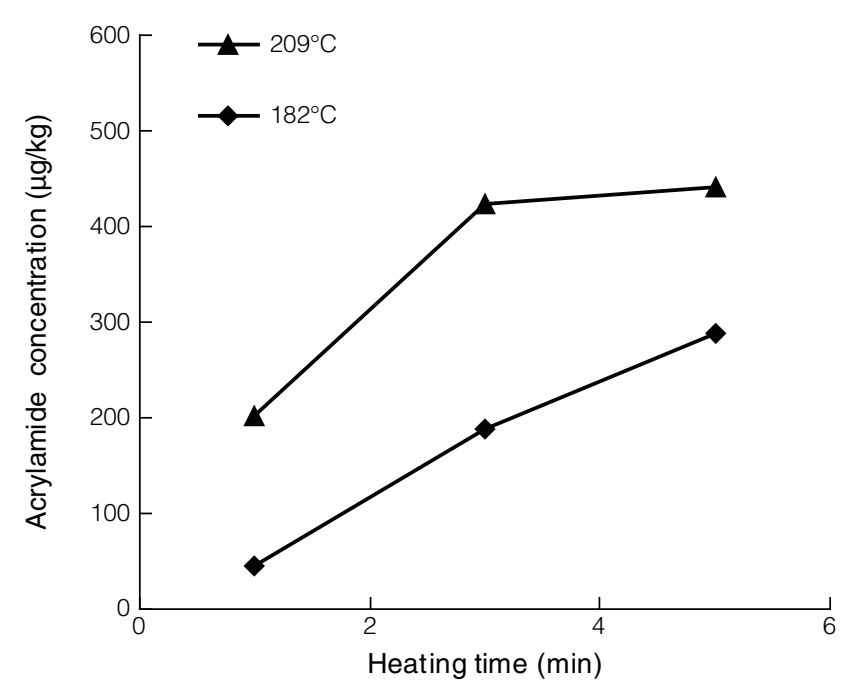

Figure 7. The effect of heating temperature and time on the acrylamide content in twisted cruller fried in oil bath.

$776 \mu \mathrm{g} / \mathrm{kg}$, which were close to those for potato chips. The old twisted cruller had higher acrylamide content (about $890 \mu \mathrm{g} / \mathrm{kg}$ ) than the twister cruller probably due to the long soaking time in the frying oil. The use of leavening agents (ammonia powder and baking powder) in the formulation might cause the high acrylamide content in twisted cruller due to the high $\mathrm{pH}$ (about 8.6) ${ }^{(28,29)}$. High frying temperature and long frying time more acrylamide as shown in Figure 7. The results were similar to those for the fried fritters ${ }^{(4)}$. Generally, a frying temperature of $209^{\circ} \mathrm{C}$ for $5 \mathrm{~min}$ was employed to prepare twisted cruller, which yielded a high acrylamide content of 441 $\mu \mathrm{g} / \mathrm{kg}$. Lowering the frying temperature from $209^{\circ} \mathrm{C}$ to $182^{\circ} \mathrm{C}$ remarkably reduced the acrylamide content, but the product was less crispy and less liked by consumers. There is a need to develop a process which produces low or zero acrylamide with texture favored by consumers.

\section{CONCLUSIONS}

The addition of triethylamine had completely converted 2, 3-DBPA to 2-BPA for determining acrylamide by GC/MS. The approach appeared to be suitable for analyzing acrylamide in food with confident recovery and a detection limit of $5 \mu \mathrm{g} / \mathrm{kg}$. The acrylamide contents in several Chinese foods including fried gluten, instant noodles, cup noodles, twisted cruller, old twisted cruller, and potato chips have been determined and compared with literature data. With little starch or carbohydrates, fried gluten appeared to have the least acrylamide content among the products tested. Probably due to the presence of leavening agents, the popular breakfast twisted cruller had the highest acrylamide content. However, the intake of those products needs to be investigated before any risk assessment can be done. 


\section{ACKNOWLEDGEMENTS}

This study is part of a research project sponsored by the Department of Health, ROC (project no. DOH92TD-1102). The financial support is greatly appreciated.

\section{REFERENCES}

1. Tareke, E., Rydberg, P., Karlsson, P., Eriksson, S. And Törnqvist, M. 2002. Analysis of acrylamide, a carcinogen formed in heated foodstuffs. J. Agric. Food Chem. 50: 4998-5006.

2. Svensson, K., Abramsson, L., Becker, W., Glynn, A., Hellenäs, K. E., Lind, Y. and Rosén, J. 2003. Dietary intake of acrylamide in Sewden. Food Chem. Toxicol. 41: 1581-1586.

3. Nemoto, S., Takatsuki, S., Sasaki, K. and Maitani, T. 2002. Determination of acrylamide in foods by GC/MS Using ${ }^{13} \mathrm{C}$-labeled acrylamide as an internal standard. J. Food Hyg. Soc. Jpn. 43: 371-375.

4. Leung, K. S., Lin, A., Tsang, C. K. and Yeung, S. T. K. 2003. Acrylamide in Asian foods in Hong Kong. Food Addit. Contam. 20: 1105-1113.

5. Murkovic, M. 2004. Acrylamide in Austrian foods. Biochem. Biophy. Methods 61: 161-167.

6. Barber, D. S., Hunt, J., Lopachin, R. M. and Ehrich, M. 2001. Determination of acrylamide and glycidamide in rat plasma by reversed-phase high performance liquid chromatography. J. Chromatogr B. 758: 289-293.

7. IARC Monographs on the evaluation of carcinogenic risks to humans, some industrial chemicals. 1994. International Agency for Research on Cancer, Lyon 60: 389-433.

8. World Health Organization. 1985. Acrylamide, environmental health criteria 49. http://www.inchem.org/ documents/ehc/ehc/ehc49.htm\#PartNumber:1. Accessed 2003 March 20.

9. Castle, L. 1993, Determination of acrylamide monomer in mushrooms grown on polyacrylamide gel. J. Agric. Food Chem. 41: 1261-1263.

10. Lagalante, A. F. and Felter, M. A. 2004. Silylation of acrylamide for analysis by solid-phase microextraction/gas chromatography/ion-trap mass spectrometry. J. Agric. Food Chem. 52: 3744-3748.

11. Wenzl, T., de la Calle, M. B. and Anklam, E. 2003. Analytical methods for the determination of acrylamide in food products: A review. Food Addit. Contam. 20: 885-902.

12. Rosén, J. and Hellenäs, K. E. 2002. Analysis of acrylamide in cooked foods by liquid chromatography tandem mass spectrometry. Analyst 127: 880-882.

13. Andrzejewski, D., Roach, J. A. G., Gay, M. L. and Musser, S. M. 2004. Analysis of coffee for the presence of acrylamide by LC-MS/MS. J. Agric. Food Chem. 52: 1996-2002.

14. Anonym. 2002. Report of the Analytical Methods
Wording Group for Acrylamide in Food Workshop: Scientific Issues, Uncertainties, and Research Strategies. October 28-30. Rosemont, Illinois, U. S. A.

15. Hoenicke, K., Gatermann, R., Harder, W. and Hartig, L. 2004. Analysis of acrylamide in different foodstuffs using liquid chromatography-tandem mass spectrometry and gas chromatography-tandem mass spectrometry. Anal. Chim. Acta 520: 207-215.

16. Center for Food Safety and Applied Nutrition/Office of Plant \& Dairy Foods and Beverages, U. S. Food and Drug Administration. 2002. Detection and Quantitation of Acrylamide in Foods. http://www.cfsan.fda. gov/ dms/acrylami.html Accessed 2003 April 10.

17. Ono, H., Chuda, Y., Ohnishi-Kameryama, M., Yada, H., Ishizaka, M., Kobayashi, H. and Yoshida, M. 2003. Analysis of acrylamide by LC-MS-MS and GC-MS in processed Japanese foods. Food Addit. Contam. 20: 215-220.

18. Becalski, A., Lau, B. P. Y., Lewis, D. and Seaman, S. W. 2003. Acrylamide in foods: Occurrence, sources and modeling. J. Agric. Food Chem. 51: 802-808.

19. Castle, L., Camp, M. J. and Gilbert, J. 1991. Determination of acrylamide monomer in hydroponically-grown tomatoes by capillary gas chromatography mass spectrometry. J. Sci. Food Agric. 54: 549-555.

20. Raymer, J. H., Sparacino, C. M. and Velez, G. R. 1993. Determination of Acrylamide in rat scrum and sciatic nerve by gas chromatography-electron-capture detection. J. chromatogr. 619: 223-234.

21. Gertz, C. and Klostermann, S. 2002. Analysis of acrylamide and mechanisms of its formation in deep-fried products. Eur. J. Lipid Sci. Technol. 104: 762-771.

22. Andrawes, F., Greenhouse, S. and Draney, D. 1987. Chemistry of acrylamide bromination for trace analysis by gas chromatography and gas chromatography-mass spectrometry. J. Chromatogr. 399: 269-275.

23. Chen, P. H., Richardson, S. D., Krasner, S. W., Majetich, G.. and Glish, G. L. 2002. Hydrogen abstraction and decomposition of bromopicrin and other trihalogenated disinfection byproducts by GC/MS. Environ. Sci. Technol. 36: 3362-3371.

24. Ahn, J. S., Castle, L., Clarke, D. B., Lloyd, A. S., Philo, M. R. and Speck, D. R. 2002. Verification of the findings of acrylamide in heated foods. Food Addit. Contam.19: 1116-1124.

25. McLafferty, F. W. and Turecek, F. 1993. Interpretation of Mass Spectra. 4th ed. pp. 339-340. University Science Books. Mill Valley, California, U. S. A.

26. Center for Food Safety and Applied Nutrition/Office of Plant and Dairy and Beverages, U. S. Food and Drug Administration. 2004a. Exploratory Data on Acrylamide in Food. http://www.cfsan.fda.gov/ dms/acrydata.html Accessed 2005 Jan. 25.

27. Center for Food Safety and Applied Nutrition/Office of Plant and Dairy and Beverages, U. S. Food and Drug Administration. 2004b. Foods Exploratory Data on Acrylamide in Food FY 2003 Total Diet Study Results. 
http://www.cfsan.fda.gov/ dms/acrydat2.html Accessed 2005 Jan. 25.

28. Jung, M. Y., Choi, D. S. and Ju, J. W. 2003. A novel technique for limitation of acrylamide formation in fried and baked corn chips and in French fries. Food Chem Toxicol. 68: 1287-1290.
29. Rydberg, P., Eriksson, S., Tareke, E., Karlsson, P., Ehrenbery, L. and Torngvist, M. 2003. Investigations of factors that influence the acrylamide content of heated foodstuffs. J. Agric. Food Chem. 51: 7012-7018. 